\title{
Adrenal Ganglioneuroma With Lymph Node Deposits: A Rare Benign Tumor
}

\author{
Suguna B Vª, Monika Lamba Saini ${ }^{\mathrm{c}, \mathrm{d}}$, Rangaswamy S R ${ }^{\mathrm{a}}$, Somashekharaiah $\mathrm{D}^{\mathrm{b}}$
}

\begin{abstract}
Ganglioneuromas are rare, benign tumors arising from primordial neural crest cells. We report a case of a seven-year-old girl presenting with a history of pain in the left side of the abdomen since one year. A provisional diagnosis of a non-functioning adrenal tumor was made on the basis of radiological scans and endocrine profile. The specimen was excised along with a lymph node. The specimen showed a grey white lesion measuring $2.5 \times 2.5 \mathrm{~cm}$. Sections from the lesion and the lymph node showed a benign tumor with spindle cells in intersecting fascicles and ganglion cells in clusters. A final diagnosis of benign ganglioneuroma was thus made. Adrenal gland ganglioneuromas with lymph node deposits represent a spontaneous differentiation from neuroblastoma in which the lymph node deposit has also matured. Representation of this entity in literature is important to alert the histopathologist for the diagnosis of a benign tumor in the primary and metastatic site.
\end{abstract}

Keywords: Adrenal; Ganglioneuroma; Lymph node

\section{Introduction}

Ganglioneuromas are rare, benign tumors arising from the undifferentiated cells of the sympathetic nervous system,

Manuscript accepted for publication August 23, 2011

aDepartment of Pathology, Kempegowda Institute of Medical Sciences, Bangalore - 560004, India

${ }^{\mathrm{b}}$ Department of Surgery, Kempegowda Institute of Medical Sciences, Bangalore - 560004, India

${ }^{\mathrm{c}}$ Department of Pathology, Cliniques universitaires Saint-Luc, Universite catholique de Louvain, Brussels, Belgium

${ }^{\mathrm{d}}$ Corresponding author: Anatomie pathologique, Cliniques universitaires Saint-Luc, Universite catholique de Louvain, B-1200 Brussels Belgium. E-mail: monikalamba@gmail.com

doi:10.4021/jnr56e also known as neural crest sympathogonia. They can be found along the sympathetic ganglia, the posterior mediastinum and retroperitoneum being the commonest sites [1]. Ganglioneuromas, represent the benign entity of the same histologic spectrum as ganglioneuroblastoma and neuroblastoma. An infrequent feature of the neuroblastoma is that it can undergo histological maturation and regress into benign ganglioneuroma [2]. This differentiation can occur spontaneously or after treatment [3]. The authors report this rare phenomenon of spontaneous maturation of neuroblastoma to ganglioneuroma and the occurrence of this phenomenon even in the metastatic site.

\section{Case Report}

A seven-year-old girl presented in the surgery outpatient department of our hospital with a history of pain in the left side of the abdomen since one year. The patient had been investigated one year earlier for the pain in the abdomen in another hospital. A radiological scan had revealed a mass in the left side of the abdomen, the details of which were not available. Biopsy was done and a diagnosis of malignant round cell tumor was given. MRI was repeated in our hospital. The scan revealed a mass measuring $6 \mathrm{~cm}$ in diameter in the suprare-

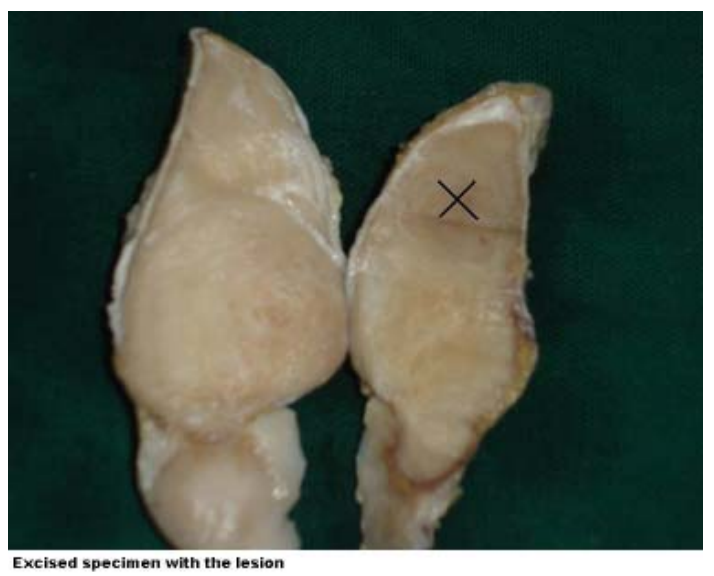

Figure 1. Gross photograph of the excised specimen with the lesion. 


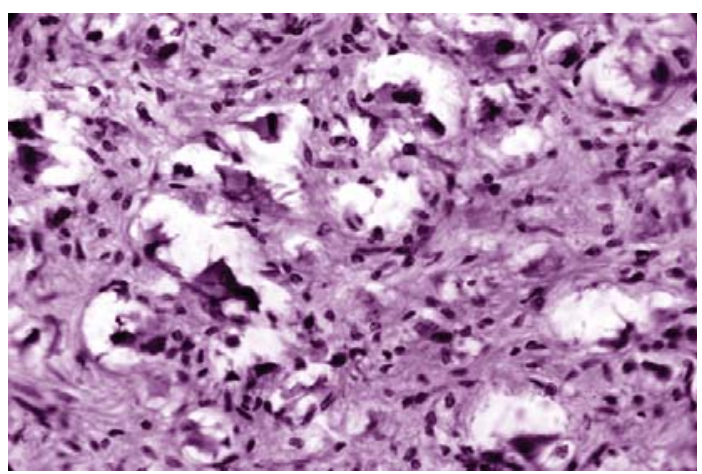

Figure 2. Mature ganglion cells surrounded by Schwann-like cells [H\&E, 40X].

nal fossa with foci of calcification and also showed calcified lymph nodes. Laboratory data including endocrinological profile was normal.

The excised specimen measured 6.5 x 2.5 x $3.5 \mathrm{~cm}$. On cut section, a well-circumscribed greyish white to yellow lesion measuring $2.5 \times 2.5 \mathrm{~cm}$ was seen (Fig. 1). There was a lymph node sent along with the excised specimen measuring $1.5 \mathrm{x} 1 \mathrm{~cm}$. The lesion and the lymph node were gritty to cut at places. Histopathological examination of both the adrenal lesion and the lymph node revealed a benign, well-circumscribed tumor showing two distinct cellular sub-groups comprising of spindle cells and ganglion cells. The spindle cells were arranged in intersecting fascicles resembling Schwannlike cells, whereas the ganglion cells were seen in clusters and also lying singly (Fig. 2). Focal peri-vascular lymphocytic infiltrate and foci of calcification were also noted. Multiple sections were taken and investigated to rule out foci of neuroblastoma. A thorough search failed to reveal any foci of neuroblastoma. Section from the surrounding adrenal gland showed compressed adrenal cortical tissue at the periphery. A diagnosis of benign adrenal ganglioneuroma was made.

\section{Discussion}

Ganglioneuromas are benign tumors of sympathetic nervous system arising from primordial neural crest cells. They share similar lineage with ganglioneuroblastoma and neuroblastoma, however they are differentiated histologically by their stage of neuroblast maturation [1]. Ganglioneuromas are at the benign end of the spectrum with presence of mature ganglion cells.

Ganglioneuromas usually occur in adolescents and young adults and show a female predominance [4]. Commonest locations of involvement are posterior mediastinum and retroperitoneum. However, ganglioneuromas have also been reported from other locations like adrenal gland, heart [5], bone [6], intestine, and parapharyngeal region [7]. As seen in this case, ganglioneuromas are diagnosed inciden- tally during imaging studies performed for other complaints like abdominal pain, fever, or abdominal mass. Ganglioneuromas can elaborate androgenic hormones or secrete vasoactive intestinal peptide leading to gastrointestinal symptoms

Grossly, ganglioneuromas are well-circumscribed lesions not exceeding $10 \mathrm{~cm}$. They are firm to touch, and appear grey-white to yellow with foci of calcification [8]. Areas of haemorrhage and necrosis are not found as they correspond to presence of neuroblastic tissue. Some tumors may also show presence of pseudocapsule.

Histologically, ganglioneuromas are fully differentiated tumors and do not show immature elements like neuroblasts or mitotic activity. They show presence of ganglion cells, Schwann cells, and stromal tissue comprising of fibrous elements, sometimes with myxoid change. Ganglion cells show abundant eosinophilic cytoplasm with prominent nuclei, and are seen in clusters, nests, or interspersed singly. Schwann cells are present as bundles which are transversely arranged with intersecting fascicles [9].

Radiographically, ganglioneuromas demonstrate calcifications on CT scan which can be fine or speculated. They appear as homogenous masses with slight to moderate enhancement. MRI reports strongly favour heterogenous high signal intensity on T2 weighted images for ganglioneuroma [10].

Ganglioneuromas may arise de novo or other malignant neuroblastic tumors may show spontaneous regression to form mature benign ganglioneuroma as seen in this case. The previous biopsy report indicates the presence of a malignant small round cell tumor, indicating the possibility of a previous neuroblastoma. However, the adrenal mass after excision had no foci of neuroblastic tissue, necrosis, or mitotic activity. Metastasis from ganglioneuroma is rare; however, the present case had a lymph node with tumor deposits in the vicinity of the main tumor mass. The lymph node showed similar histologic features as the main tumor.

Enzinger and Weiss [11] have proposed that these tumors represent neuroblastoma in which the metastasis as well as the primary tumor has matured. Ganglioneuromas usually result due to maturation of neuroblastoma cells to ganglion cells. Some old reports also believe that ganglioneuroma results from necrosis of immature neuroblasts occurring in a tumor mass leaving behind mature ganglion cells [12]. However, this theory does not stand true in spontaneous regression seen in metastatic sites.

Rarely, neuroblastoma undergoes spontaneous maturation to form ganglioneuroma. This process can occur spontaneously or can follow chemotherapeutic treatment of neuroblastoma. The process of spontaneous maturation in the primary as well as metastatic site is not clear, although spontaneous regression of Stage IV tumors have also been reported [13].

Surgical excision warrants complete cure in almost all the patients [14]. Ganglioneuromas, thus should be exam- 
ined thoroughly to exclude any foci of neuroblastoma. A deposit in the lymph node of this benign tumour alerts the histopathologist but a careful literature search reveals that ganglioneuromas can arise from a neuroblastoma in which the primary tumour and the lymph node deposit have undergone a spontaneous differentiation.

\section{Conclusion}

Adrenal gland ganglioneuroma are rare, benign tumors and pre-operative diagnosis is difficult. Occurrence of spontaneous regression of neuroblastoma to ganglioneuroma is rare as seen in this case. Metastasis to the lymph node is of interest. Rarity of the case and the phenomenon of spontaneous regression in the primary and metastatic site warrant its documentation in literature.

\section{Conflict of Interest}

None declared.

\section{Ethical Issues}

There were no ethical issues involved as the investigations and excision were done as a part of the treatment for which necessary consent was taken from the patient. Approval was also sought for publication from the patient.

\section{References}

1. Patterson AR, Barker CS, Loukota RA, Spencer J. Ganglioneuroma of the mandible resulting from metastasis of neuroblastoma. Int J Oral Maxillofac Surg. 2009;38(2):196-198.

2. Cushing H, Wolbach SB. The Transformation of a Malignant Paravertebral Sympathicoblastoma into a Benign Ganglioneuroma. Am J Pathol. 1927;3(3):203-216 207.

3. Bhattacharyya I, Williamson A, Cohen DM, Bever JL. Metastatic neuroblastoma with ganglioneuromatous dif- ferentiation and mandibular involvement. Oral Surg Oral Med Oral Pathol Oral Radiol Endod. 1999;88(5):586592.

4. Geoerger B, Hero B, Harms D, Grebe J, Scheidhauer K, Berthold F. Metabolic activity and clinical features of primary ganglioneuromas. Cancer. 2001;91(10):19051913.

5. Jain M, Shubha BS, Sethi S, Banga V, Bagga D. Retroperitoneal ganglioneuroma: report of a case diagnosed by fine-needle aspiration cytology, with review of the literature. Diagn Cytopathol. 1999;21(3):194-196.

6. Freeman BD, Zuckerman GR, Callery MP. Duodenal ganglioneuroma: a rare cause of upper GI hemorrhage. Am J Gastroenterol. 1996;91(12):2626-2627.

7. Albonico G, Pellegrino G, Maisano M, Kardon DE. Ganglioneuroma of parapharyngeal region. Arch Pathol Lab Med. 2001;125(9):1217-1218.

8. Rha SE, Byun JY, Jung SE, Chun HJ, Lee HG, Lee JM. Neurogenic tumors in the abdomen: tumor types and imaging characteristics. Radiographics. 2003;23(1):29-43.

9. Okamatsu C, London WB, Naranjo A, Hogarty MD, Gastier-Foster JM, Look AT, LaQuaglia M, et al. Clinicopathological characteristics of ganglioneuroma and ganglioneuroblastoma: a report from the CCG and COG. Pediatr Blood Cancer. 2009;53(4):563-569.

10. Ichikawa T, Ohtomo K, Araki T, Fujimoto H, Nemoto K, Nanbu A, Onoue M, et al. Ganglioneuroma: computed tomography and magnetic resonance features. Br J Radiol. 1996;69(818):114-121.

11. Enzinger FM, Weiss SW. Soft tissue tumours.2nd ed. St. Louis: Mosby; 1988.

12. Landing B. Thoracic ganglioneuroma with hypertension. In: Del Regato JA, ed. Cancer in Children: Cancer Seminar. 1957; 2 : 94-96.

13. Haas D, Ablin AR, Miller C, Zoger S, Matthay KK. Complete pathologic maturation and regression of stage IVS neuroblastoma without treatment. Cancer. 1988;62(4):818-825.

14. Daljeet Singh, Amreek Singh, B. R. Prabhakar, Raman Arora, Satish Jain, G. S. Hara, Lovneesh Garg, R. S. Sibia .Ganglioneuroma of the adrenal gland. Indian Journal of Surgery. 2003; 65: 436-438. 